\title{
Numerical modeling of snow cover over polar ice sheets
}

\author{
Hervé Dang, ${ }^{1}$ Christophe Genthon, ${ }^{1}$ Eric Martin ${ }^{2}$ \\ ${ }^{1}$ Laboratoire de Glaciologie et Géophysique de l'Environnement, CNRS, \\ Associé à l'Université foseph-Fourier, 54 rue Molière, BP 96, 38402 St-Martin-d'Hères Cedex, France \\ ${ }^{2}$ Centre d’Études de la Neige, Météo-France, 1441 rue de la Piscine, 38406 St-Martin-d'Hères Cedex, France
}

\begin{abstract}
Crocus, a one-dimensional model of snow-cover stratigraphy and evolution, was developed by the Centre d'Études de la Neige (CEN, Météo-France) and extensively validated in temperate Alpine conditions. We present here a study of Crocus's ability to reproduce the characteristics of polar snow at the surface of ice sheets. Crocus simulates the evolution of the thermal and structural features of snow cover as a function of meteorological parameters at the snow-atmosphere interface. Only models can provide the necessary meteorological information with full ice-sheet spatial coverage, and with the temporal resolution needed by Crocus. Meteorological data have been extracted from the European Centre for Medium-Range Weather Forecasts (ECMWF) archives (analyses and short-term predictions), over the entire surface of Antarctica with a spatial resolution of $1.5^{\circ}$. Here, the ECMWF data from the South Pole are first compared with observations to check their quality. Then, 20 year simulations of snow cover are computed to test the sensitivity of Crocus to inaccuracies in the meteorological input. The simulated snow characteristics exhibit a strong sensitivity to air temperature, accumulation rate and the initial density of depositing snow. However, even with no major model adaptation to polar conditions, Crocus does reproduce a number of thermal and structural features of polar snow.
\end{abstract}

\section{INTRODUGTION}

A good numerical model of the physical characteristics of snow cover at the surface of polar ice sheets has applications in numerous fields of polar climate and environment research, including the study and understanding of atmosphere snow exchange of energy, momentum and matter (such as atmospheric composition and impurities, the interpretation of satellite data, and the quantification of the processes of transformation and sintering of snow into firn and then into ice.)

Crocus (Brun and others, 1989, 1992) is a one-dimensional (1-D) model of snow-cover evolution. The main snow-cover characteristics simulated by Crocus and their evolution with time are strongly governed by surface meteorological conditions. Therefore, Crocus needs hourly meteorological input data.

Initially, Crocus was set up and adjusted for snow modeling under temperate Alpine meteorological conditions, and it is used operationally for avalanche forecasting. For polar applications, all the necessary meteorological data are or have been directly observed at a few sites and over limited time periods only. On the other hand, more than 15 years of analyses and short-term predictions are archived at the European Centre for Medium-Range Weather Forecasts (ECMWF) at Reading in the UK, and are available every six hours at a spatial resolution of up to $0.5^{\circ}$ all over the globe. The analyses and short-term predictions are constrained by the synoptic observations provided by the World Meteorological Organisation network. As these observations are rare in polar regions, the constraint at global scale is rather low. In addition, radiation and precipitation are not systematically observed, and are not used as constraints for meteorological analysis and prediction. The ECMWF archive is thus largely a climate-model product over the polar ice sheets. The data quality and the possible consequences of inaccuracies in Crocus have to be carefully checked.

Crocus has been validated for temperate Alpine snows. In polar conditions (cold temperature, low precipitation, polar radiative cycle), some of the current parameterizations may well reach their limit of validity. An extreme test site has to be chosen to check this aspect. The South Pole permanent station is probably the best possible site, for which comparatively good snow and meteorological observations are available.

\section{CROCUS}

The Crocus model has been described in detail by Brun and others $(1989,1992)$, and so only a brief description of the model and the initial and boundary conditions is given here.

Crocus simulates the energy and mass evolution of a 1-D snow cover which is considered as a stack of layers (maximum $=50$ ) that are parallel to the slope, and the energy exchanges are projected perpendicular to the slope. Each snow layer is characterized by its thickness, temperature, density, liquid water content, grain-size, grain sphericity and grain age. To run the model, an initial snow profile is needed. The evolution of the snow characteristics depends on meteorological parameters, which are needed at an hourly step. These parameters are: $2 \mathrm{~m}$ air temperature, surface wind, air humidity, precipitation (amount and phase), 


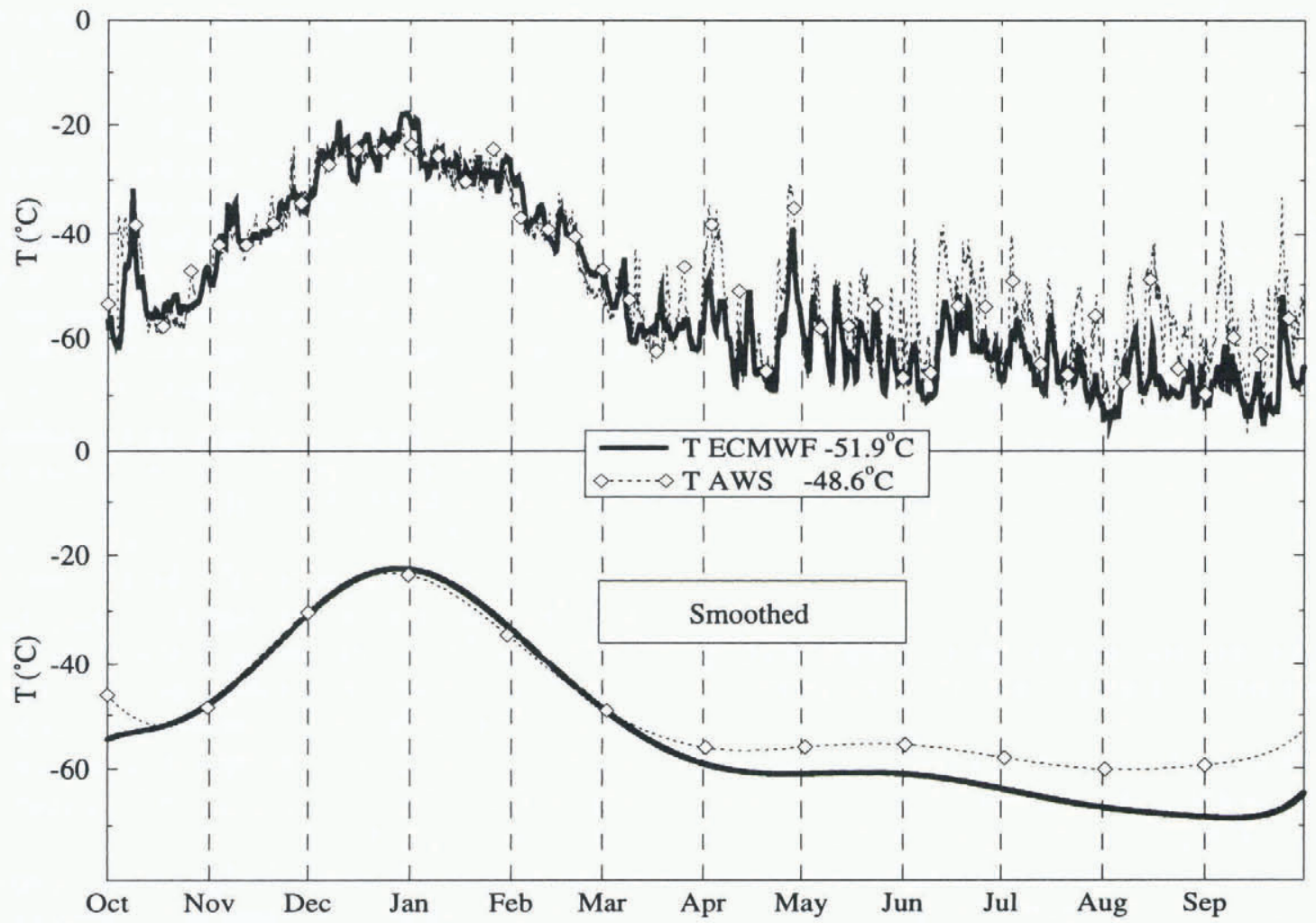

Fig. 2. Daily mean air temperature at the South Pole between 1 October 1991 and 30 September 1992. Numbers in parentheses are annual means.

The ECMWF archive is a well-known high-quality source of meteorological data, yet comparison with AWS and other observations shows some inaccuracy over Antarctica. The sensitivity of the snow model to meteorological input uncertainties must be evaluated in order to estimate the potential quality of future large-scale simulations of the snow cover in polar regions using ECMWF data.

\section{SNOW SIMULATIONS AT THE SOUTH POLE}

A set of 20 year snow simulations has been computed in order to characterise Crocus's sensitivity to air temperature, incident infrared radiation, surface density of fresh snow and inter-annual variation in accumulation (Table 1). To cover 20 years, the ECMWF-derived one year meteorolog-

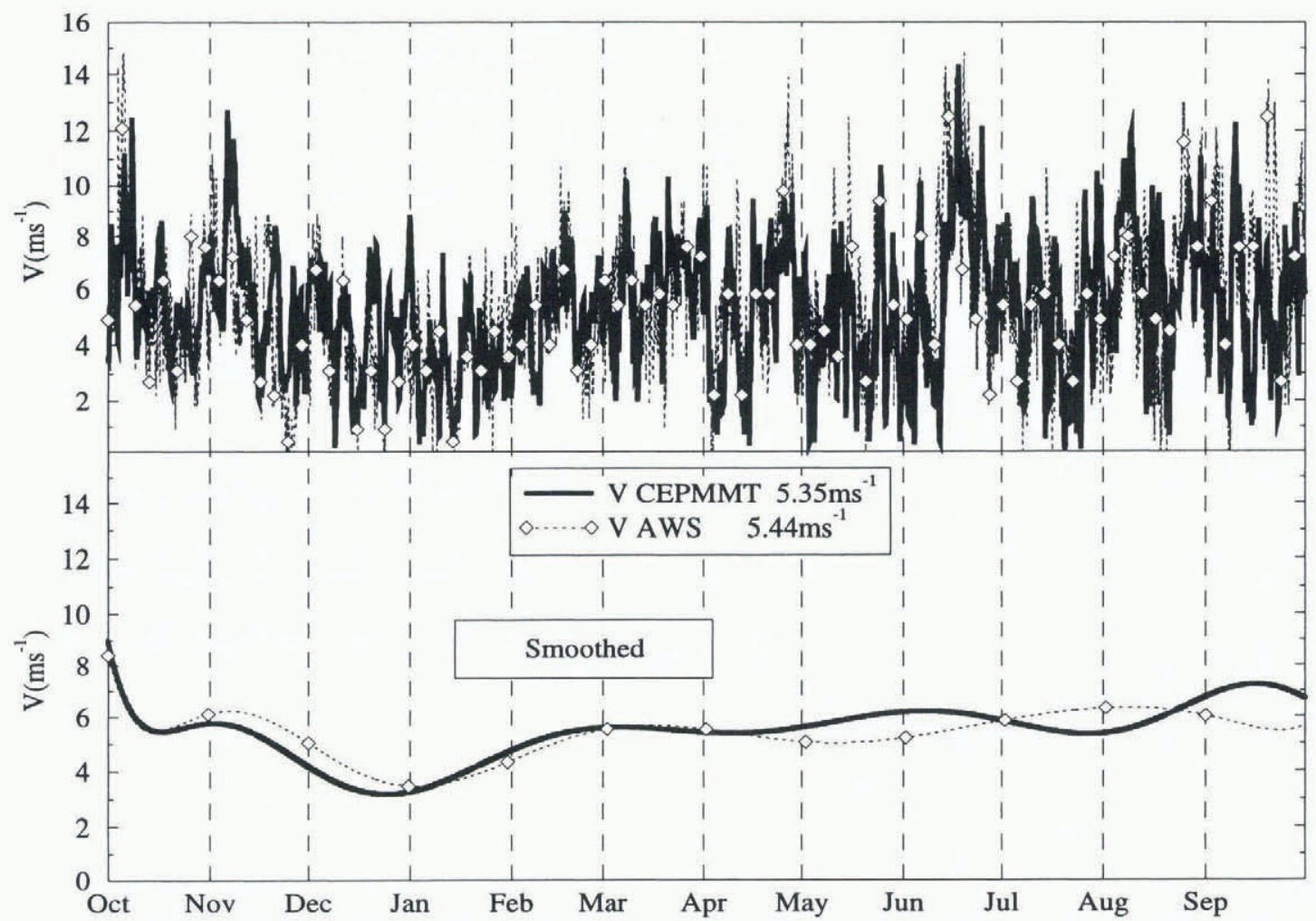

Fig. 3. Daily mean wind speed at the South Pole between 1 October 1991 and 30 September 1992. Numbers in parentheses are annual means. 
Table 1. Sensitivity simulations performed

Simulation Characteristics

A Meteorological forcing from the ECMWF archive, except for $2 \mathrm{~m}$ air temperature from the AWS.

Surface snow density is prescibed at $0.35 \mathrm{~g} \mathrm{~cm}^{-3}$.

B Meteorological forcing from the ECMWF archive, including $2 \mathrm{~m}$ air temperature.

Surface snow density is prescribed at $0.35 \mathrm{~g} \mathrm{~cm}^{-3}$.

C Same as A, but with a $10 \mathrm{Wm}^{-2}$ increase of incident infrared radiation.

D

Same as A, but surface snow density is prescribed at $0.30 \mathrm{~g} \mathrm{~cm}^{-3}$.

D'

Same as B, but surface snow density is prescribed at $0.30 \mathrm{~g} \mathrm{~cm}^{-3}$.

E Same as A, but with year-to-year precipitation perturbations.

F Same as A, but with surface density parameterized as a function of temperature and wind speed.

G Same as F, but with year-to-year precipitation perturbations.

ical dataset described above is used cyclically. As interannual accumulation variations must be accounted for (sec next), it will be introduced by perturbing the one year set.

\section{Temperature in the snow cover}

Figure 4 presents the mean monthly temperature profiles for six selected months inside the snow cover down to $2 \mathrm{~m}$. Three simulations have been done, and are compared to observations reported by Dalrymple (1966) for 1957-58. In the first test (simulation A), the model is forced by ECMWF archived data for the South Pole, except for air temperature, which is retrieved from the AWS observation. In simulation $\mathrm{B}$, the full ECMWF meteorology is used, including the coldbiased analysed surface temperature. Finally simulation C reproduces the conditions of simulation $\mathrm{A}$, but with the infrared budget increased by $10 \mathrm{~W} \mathrm{~m}^{-2}$.

The impact of the somewhat low ECMWF air temperature can be seen during the winter months (July, September and October). Forcing with the AWS temperature instead leads to a very clear improvement of the simulated thermal profiles for all months of the year. Therefore, Crocus does correctly simulate the transfer of heat through the snow cover, but model sensitivity to an expected error of atmospheric temperature forcing is significant. On the other hand, simulation $\mathrm{C}$ shows little sensitivity to errors of infrared radiation forcing, even during the polar night when thermal radiation is a dominant component of the surface heat budget.

\section{Density, grain-size and shape}

We now consider the structural snow-cover characteristics simulated by Crocus: snow density, grain-size and grain shape (Fig. 5). The observations of density and grain-size were obtained by J. R. Petit (personal communication, December 1975). Additional grain-size observations, plotted in Figure 5b, were reported by Gow (1969). Only qualitative reports of grain shape are available to compare with model results.

Simulations A and B yield similar, monotonous, density profiles down to $1.5 \mathrm{~m}$, but below this depth the two profiles differ significantly. This is because the present densification
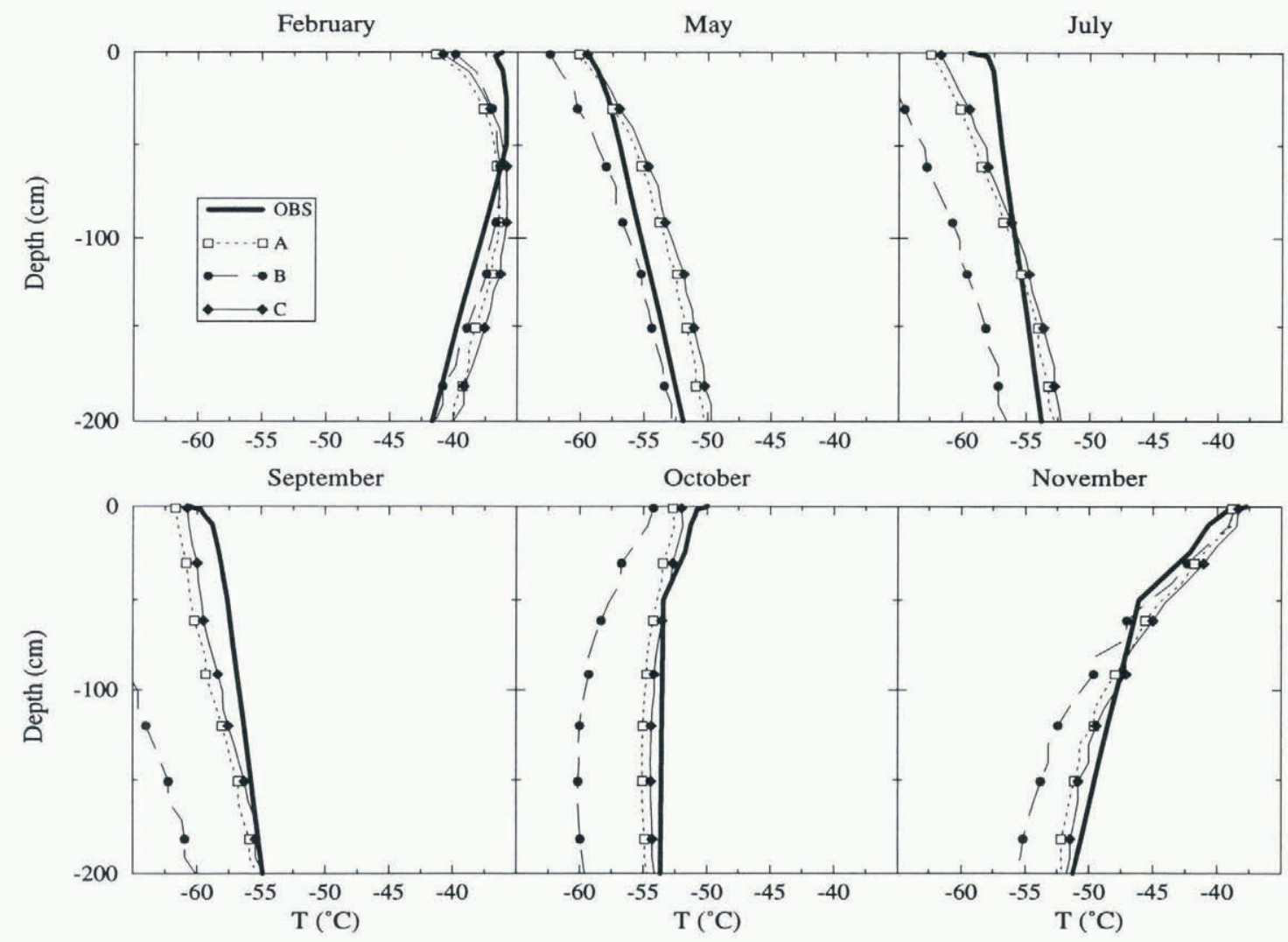

Fig. 4. Mean monthly temperature profiles inside the snow cover. The observations are from Dalrymple (1966). Details of simulations $A, B$ and $C$ are given in the main text and Table 2. 
formulation in Crocus only takes into account the settling by the weight of overlying snow layers, with a compactive viscosity depending on local density and temperature. In practice, weight-induced densification becomes efficient below $1.5 \mathrm{~m}$ only, but observations show a rapid succession of layers of distinctive densities in the first meter. In fact, a fast densification process takes place right at the surface, due to wind mechanical forcing and the breaking of branched crystals (recently deposited at low density) followed by grain aggregation. This is not yet adequately accounted for by Crocus.

Model results are very sensitive to the initial surface density of fresh snow deposited at the surface. In standard Crocus, deposited snow density is parameterized using the Pahaut formula (Durand and others, 1993), which is based on wind speed and air temperature. The formula is valid for temperate regions, but gives strongly underestimated densities in the polar temperature range. In the cold and windy polar regions, the measured surface densities are generally in the range of $0.3-0.45 \mathrm{~g} \mathrm{~cm}^{-3}$. The mean surface density at the South Pole is about $0.35 \mathrm{~g} \mathrm{~cm}^{-3}$. This value was used for simulation A and B.

Except for the rapid fluctuations (see above), the simulated density profiles show good agreement with observation (Fig. 5a). To test the sensitivity of the results to this parameter, two simulations $\mathrm{D}$ and $\mathrm{D}^{\prime}$ (respectively with AWS and ECMWF air temperature) have been performed with an imposed initial density reduced to $0.35 \mathrm{~g} \mathrm{~cm}^{3}$. In Figure $5 \mathrm{a}$, the simulation $\mathrm{A}$ should be compared to $\mathrm{D}$, and $\mathrm{B}$ to $\mathrm{D}^{\prime}$. Even though the surface density error decreases with depth (from 0.05 at the surface, to 0.02 at $3 \mathrm{~m}$ depth), it propagates deep into the snow cover. It is apparent that the ECMWF temperature error tends to slow down densification in simulation $\mathrm{D}^{\prime}$ compared to D. Clearly, the development of a suitable and precise parameterization of the initial surface density is an important aspect of the adaptation of Crocus for the polar regions. This point is addressed again next in simulations Fand G.

Grain-size and grain-shape (sphericity) profiles are plotted in Figures 5b and 5c. Crocus simulates a regular succession of small, rounded and large-faceted grain layers. The large-faceted grains correspond to depth hoar formed near the surface in the region of high temperature gradient (Marbouty, 1980). In simulation A, Crocus appears to simulate more depth hoar than observed (qualitative observations not shown). Perla and Ommanney (1985) have verified experimentally that low densities favor depth hoar, but high densities $\left(>0.2 \mathrm{~g} \mathrm{~cm}^{-3}\right)$ inhibit depth-hoar formation. However, the current parametric laws of Crocus allow this formation, even for the high snow densities measured at the South Pole. Also, the current Crocus law governing the evolution of grain-size allows grain growth when the temperature gradient is strong if the faceted state is fully reached (sphericity $=0$ ). As a consequence, the model grains only grow near the surface. However, J. R. Petit's observations suggest that grain-size still evolves and increases below $2 \mathrm{~m}$, even though temperature gradients are small. The isothermal processes that control grain growth at depth (Gow, 1969, Alley, 1988) are not currently formulated in the model, and need to be implemented.

The regularity of year-to-year layer succession is the result of forcing the model with a constant annual precipitation. Yet, inter-annual accumulation variability is high in Antarctica. Simulation $\mathrm{E}$ has been computed with variable annual precipitation rates. Instead of using a constant annual precipitation rate, we defined arbitrarily a four year
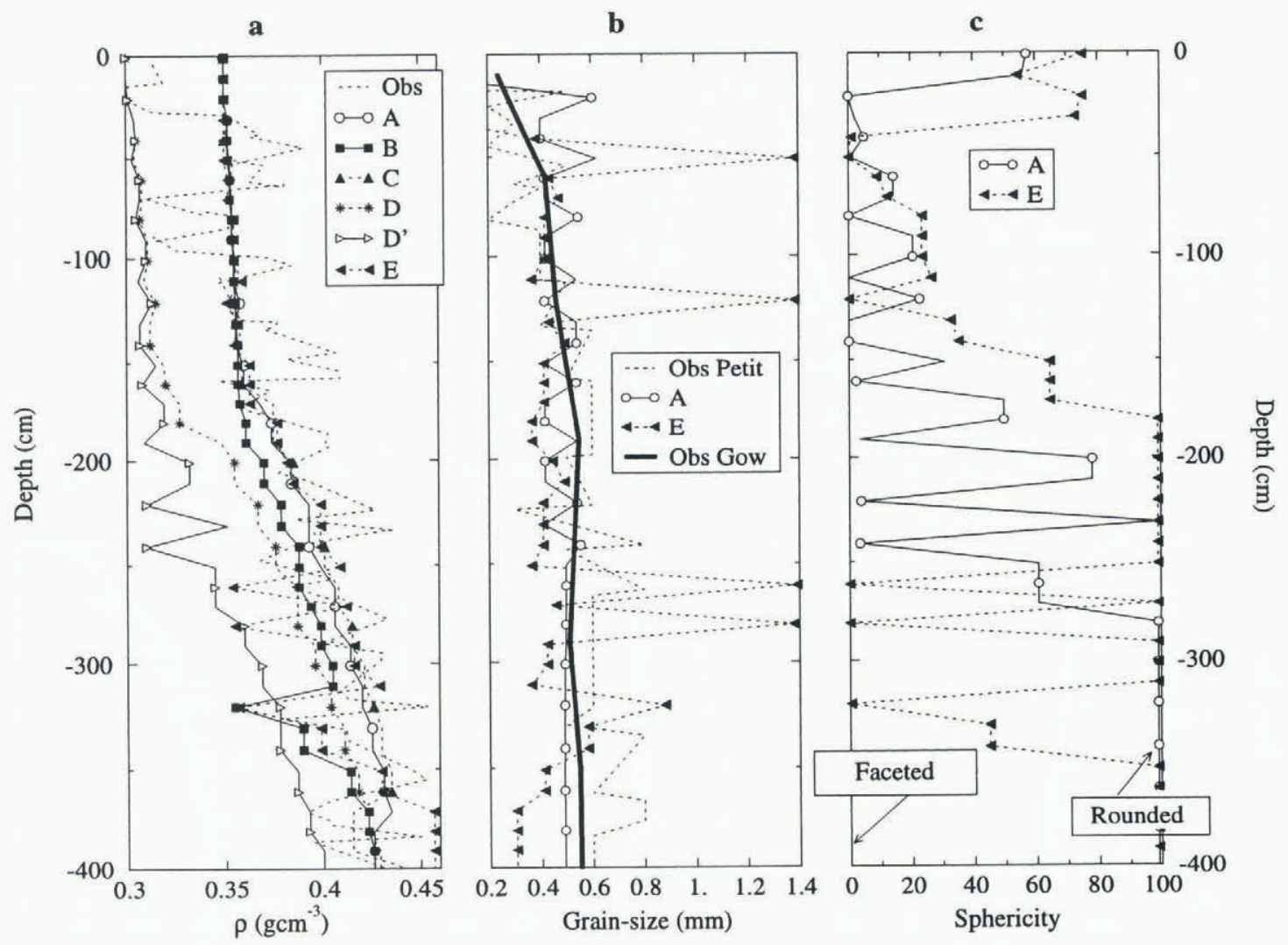

Fig. 5. Snow-density (a), grain-size (b) and sphericity (c) profiles inside the snow cover. Details of simulations $A, B, C, D, D^{\prime}$ and $E$ are given in the main text and Table 2. Density observations are from J.R. Petit (personal communication). Grain-size observations are from Gow (1969) and 7. R. Petit (personal communication, 1975). 
cycle for precipitation, in which the value of the previous simulations is respectively multiplied by $1.0,0.5,2$ and 0.5 . As all the results shown here come from 20 year runs, this cycle is repeated five times. Results (Fig. 5b) clearly show the importance of this meteorological parameter for the grain-size evolution. When precipitation is less, deposited snow stays longer near the surface and is thus more durably exposed to strong temperature gradients. It is more likely to become faceted, and to grow to large particles of up to several millimeters (Nishimura and Maeno, 1984, 1985) (see levels $-50 \mathrm{~cm}$ and $-120 \mathrm{~cm}$ in Fig. $5 \mathrm{~b}$ and c). With increased annual precipitation rate, grains are smaller and less faceted (between $-70 \mathrm{~cm}$ and $-110 \mathrm{~cm}$ ) or completely rounded (between -180 and $-250 \mathrm{~cm}$ ).

In order to define more accurately the sensitivity of the model to the initial surface density, two additional simulations were performed. The setting of simulation $\mathrm{F}$ was identical to A, except for the density of freshly deposited snow, which is a function of air temperature and of wind speed. The Pahaut parameterization is used with modified parameters. In simulation $\mathrm{G}$, the accumulation was also disturbed as in simulation E. Figure 6 compares observations with simulations $\mathrm{F}$ and $\mathrm{G}$. Large density variations are simulated near the surface, which are in good agreement with observations (Fig. 6a). However, densification smooths the variations below $1.5 \mathrm{~m}$, whereas observations show that they are preserved at depth. The most interesting aspect of these simulations is the impact on grain-size and shape profiles (Fig 6b and c). In simulation F, grains do not evolve much and remain close to a diameter of $0.4 \mathrm{~mm}$ all the way down to a depth of $4 \mathrm{~m}$. In particular, grains do not reach the state of depth hoar (Fig. 6c), while in simulation. A depth hoar was formed excessively frequently. The differences between simulations $\mathrm{A}$ and $\mathrm{F}$ are the consequences of snow density on the simulated temperature gradients near the surface, which are lower for simulation F and thus lead to much slower grain evolution. However, because interannual variations in accumulation induce strong interannual variability of near-surface temperature gradients (see the discussion of experiment $\mathrm{E}$ ), simulation $\mathrm{G}$ does, from time-to-time, reproduce depth-hoar layers in qualitative agreement with observations (levels -170 and $-255 \mathrm{~cm}$ ).

\section{CONCLUSIONS}

We have presented the results of an analysis of Crocus's ability to simulate the physical characteristics of polar snow at the surface of ice sheets with simple and straightforward adaptations of the snow model.

Meteorological analyses and predictions constitute the only possible source of data for large-scale forcing of the model. Yet we find that, over Antarctica (in fact, at the South Pole), the necessary meteorological data archived at ECMWFare not in full agreement with direct observations. Our tests indicate that the model is sensitive to air temperature errors. This dependency is significant for temperature profiles inside the snow cover, but less important for snow density and grain-size modeling. The uncertainty on the infrared radiation budget has a low impact on the simulation. On the other hand, accumulation variability is an important factor for grain-size evolution.

The density and grain-size of surface snow are functions of the meteorological parameters (air temperature and wind speed), which strongly condition the evolution of the snow cover. Therefore the formulations of these initial values need to be adapted to polar meteorological conditions. a

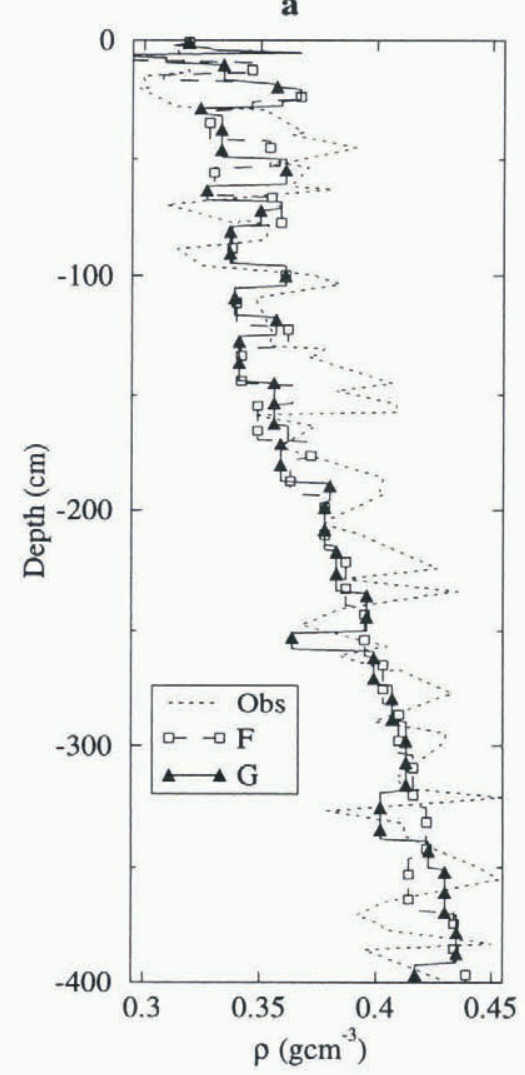

b

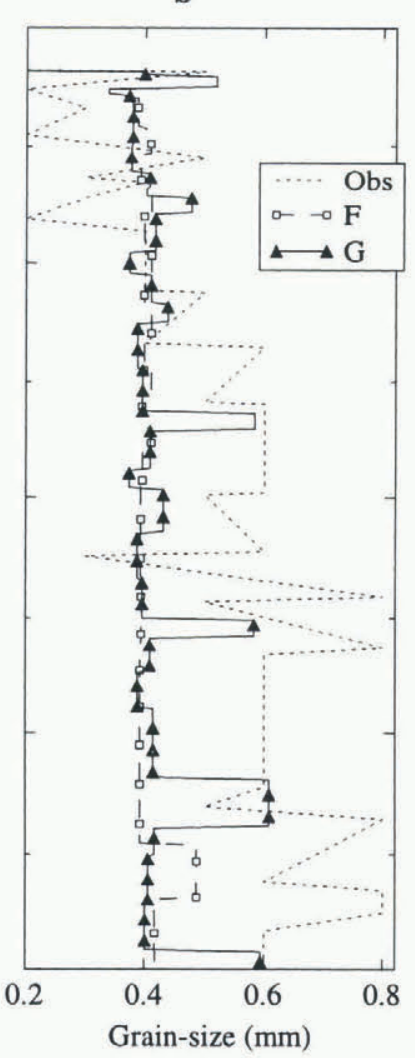

c

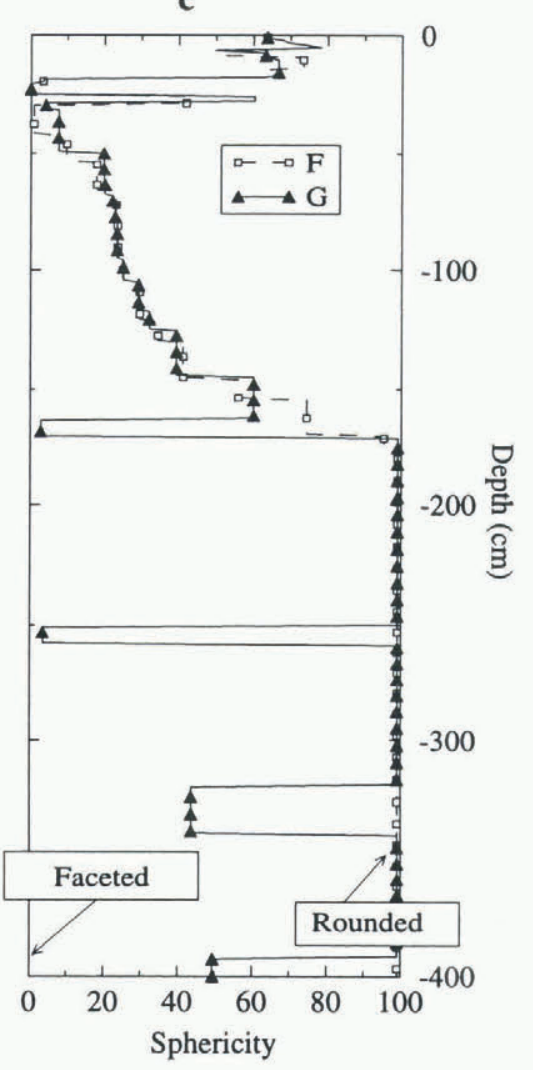

Fig. 6. Snow-density (a), grain-size (b) and sphericity (c) profiles inside the snow cover. Details of simulations $F$ and $G$ are given in the main text and Table 2. Observations are from J. R. Petit (personal communication, 1975). 
The results of this study are quite encouraging because, even with minor adaptations to polar conditions, Crocus simulates many important aspects of polar snow-cover evolution. Research will be continued through a project of the European Commission Environment and Climate Program that will see collaboration between the Laboratoire de Glaciologie et Géophysique de l'Environnement, the Centre d'Études de la Neige, the British Antarctic Survey, and the University of Barcelona.

\section{ACKNOWLEDGEMENTS}

This research was supported by the Directorate General XII of the European Commission (contract ENV4-CT950076).

\section{REFERENCES}

Alley, R. B., 1988. Concerning the deposition and diagenesis of strata in polar firn. f. Glaciol., 34(118), 333-342.

Brun, E., E. Martin, V. Simon, C. Gendre and C. Coléou. 1989. An energy and mass model of snow cover suitable for operational avalanche forecasting. J. Glaciol., 35 (121), 333-342.
Brun, E., P. David, M. Sudul and G. Brunot. 1992. A numerical model to simulate snow-cover stratigraphy for operational avalanche forecasting. 7. Glaciol., 38 (128), 13-22.

Carroll, J.J. 1982. Long-term means and short-term variability of the surface energy balance components at the South Pole. 7. Geophys. Res., 87 (C6), 4277-4286.

Dalrymple, P. C. 1966. A physical climatology of the Antarctic Plateau. In Rubin, M.J., ed. Studies in Anlartic meteorology. Washington, DC, American Geophysical Union, 195 - 231. (Antarctic Research Series 9.

Durand, Y., E. Brun, L. Mérindol, G. Guyomarc'h, B. Lesaffre and E. Martin. 1993. A meteorological estimation of relevant parameters for snow models. Ann. Glaciol., 18, 65-71.

Gow, A. J. 1969. On the rates of growth of grains and crystals in South Polar firn. f. Glaciol., 8 (53), 241-252.

Keller, L. M., G. A. Weidner and C. R. Stearns. 1993. Antarctic automatic weather station data for the calendar year 1992. Madison, WI, University of Wisconsin. Department of Meteorology.

Marbouty, D. 1980. An experimental study of temperature-gradient metamorphism. f. Glaciol., 26 (94), 303-312.

Nishimura, H. and N. Maeno. 1984. Snow structure and depth hoar formation in Mizuho plateau, Antarctica. National Institute of Polar Research. Memoirs. Special Issue 34, 137-146.

Nishimura, H. and N. Maeno. 1985. Studies on structures and physical properties of snow on Mizuho Plateau, Antarctica. Ann. Glaciol., 6, 105107.

Perla, R. and C. S. L. Ommanney. 1985. Snow in strong or weak temperature gradients. Part I: Experiments and qualitative observations. Cold Reg. Sci. Technol., 11 (1), 23-35. 